\title{
Study on thermal drying efficiency and odor emission characteristics of municipal solid waste (MSW)
}

\author{
Chun-ping LI \\ Beijing Building Materirals Academy of Science Research/State Key Laboratory of Solid Waste \\ Reuse for Building Materials, Beijing 100041, China \\ email: lichp-xj@163.com
}

Keywords: Municipal solid waste (MSW); Thermal drying; Temperature; Moisture content; Odor.

\begin{abstract}
Thermal drying efficiency and odor emission characteristics under different temperature of municipal solid waste (MSW) were studied. The results showed that: water content decreased sharply with disturbance thermal drying mode. The highest peak of total amount of odor was at $600^{\circ} \mathrm{C}$ and the lowest was at $500^{\circ} \mathrm{C}$. The highest peak of odor concentration was at $700^{\circ} \mathrm{C}$, followed by $200^{\circ} \mathrm{C}$ 、 $600^{\circ} \mathrm{C}$ and $800^{\circ} \mathrm{C}$. From the view of engineering application, considering total amount of odor and the odor concentration, thermal drying temperature should be $100^{\circ} \mathrm{C}, 300^{\circ} \mathrm{C}, 400^{\circ} \mathrm{C}$ and $500^{\circ} \mathrm{C}$.
\end{abstract}

\section{Introduction}

Incineration technology is thought to be the most effective means of urban garbage harmless, reduction and recycling ${ }^{[1]}$, but the moisture contents of MSW in China were generally more than $50 \%$ and calorific value were lower ${ }^{[2,3]}$ and, the high moisture contents has become main source of leachate during landfill, incineration and composting treatments ${ }^{[4]}$. Therefore, the important pre-treatment is to reduce the moisture content before MSW incineration.

Biological drying technology was usually used in MSW incineration plants in order to reduce the moisture contents of raw MSW. Namely, using thermopiles aerobic fermentation process of organic matter degradation, as well as process control, to promote water evaporation and realize the rapid removal of moisture ${ }^{[5]}$. Thermal drying technology is generally used for sludge ${ }^{[6]}$, research on MSW thermal drying is rare.

The use of thermal drying process will inevitably produce odor ${ }^{[7]}$. Xiong Y G et al have studied odor discharging characteristic of sludge indirect and direct thermal drying process ${ }^{[8,9]}$. Due to MSW thermal drying process has not carried out, therefore, study of odor emission characteristics concentrated more in biological drying or compost field ${ }^{[10]}$, less research focused on odor emissions during the process of MSW thermal drying.

In this study, self-made thermal drying device ${ }^{[11]}$ was used to disclose MSW thermal drying efficiency and odor volatilization characteristics, so as to provide a theoretical basis in MSW thermal drying engineering application.

\section{Materials and methods}

The experiment was conducted in March 2015. Amounts of $100 \mathrm{~kg}^{[12,13]}$ of MSW were collected in MSW transfer station in Beijing, and the thermal drying simulation experiment is carried out in the self-made thermal drying device.

Weight loss method was used to determine moisture contents. Odor samples were collected, tested and analyzed at different drying temperature according to the references [14] and GB/T14675-1993. 


\section{Results and discussion}

(1) Thermal drying efficiency of MSW

Three ovens were prepared and 20kg MSW were put into each ovens after temperature set to $100^{\circ} \mathrm{C}$. Baking time lasted for 10 hours and moisture was tested every 10 minutes, every 3 hours and every 30 minutes with manual flip 1 times. The drying efficiency of three different drying modes is shown in Figure 1.
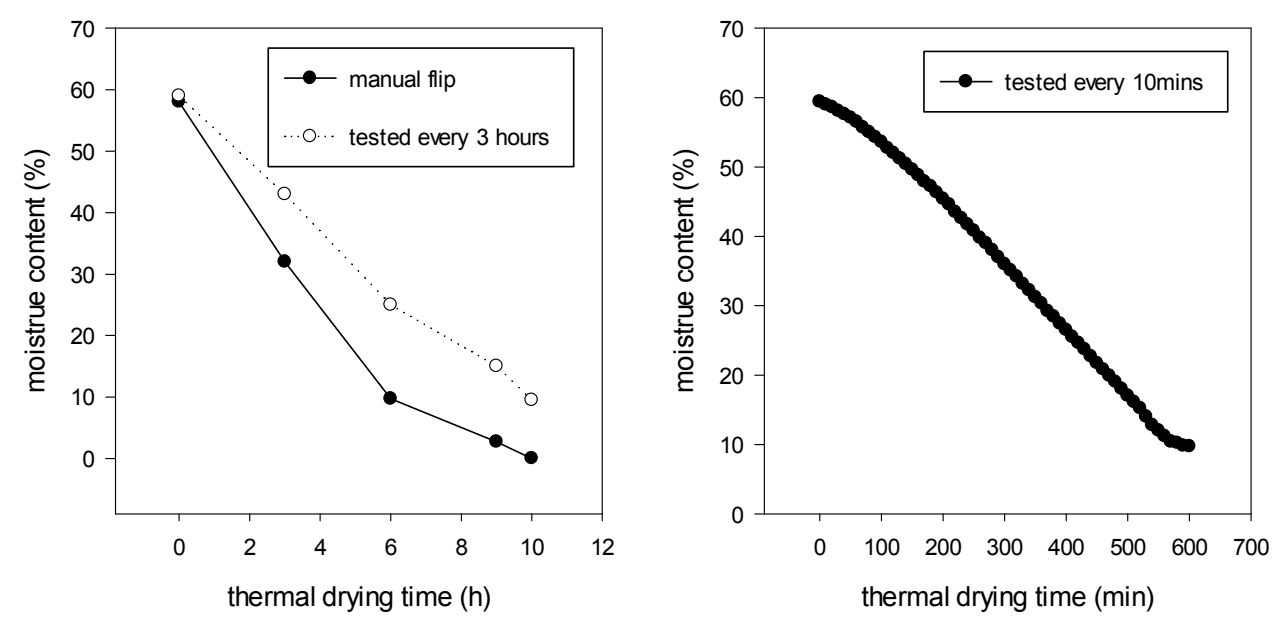

Fig. 1 Efficiency comparison of three different thermal drying mode

It can be seen from the figure 1: although baking time all lasted for 10 hours, moisture content with manual flip mode dropped to $2.7 \%$, the lowest value while with every 3 hours mode, dropped to $9.5 \%$. When MSW was tested every 10 minutes, the moisture content was still up to $9.7 \%$ due to heat losing. Therefore, in the engineering of MSW thermal drying, rotary equipment will be preferred in order to quickly reduce the moisture content and improve the efficiency of the drying.

(2) Odor composition under different thermal drying temperature

Using nitrogen as carrier gas, $20 \mathrm{~kg}$ MSW were put into ovens after temperature set to $100^{\circ} \mathrm{C}$ $\sim 800^{\circ} \mathrm{C}$, respectively. Odorous gases were sampled and tested under different drying temperature. The results were shown in figure 2.

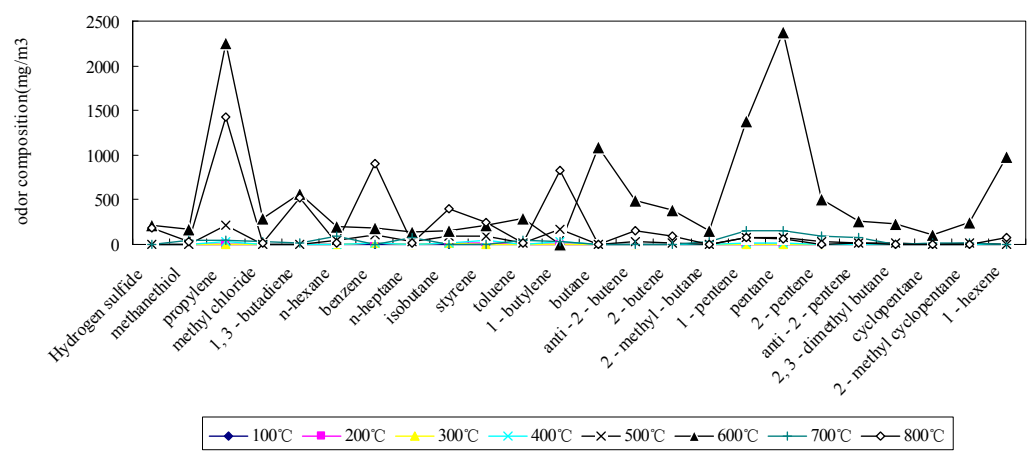

Fig. 2 odor composition under different thermal drying temperature

Odor compositions under different thermal drying temperature were different: 50 kinds of odour were discharged under $100^{\circ} \mathrm{C}$ and concentration of naphthalene is the highest with the value of 3.533 $\mathrm{mg} / \mathrm{m} 3,60$ kinds of odour were discharged under $200^{\circ} \mathrm{C}$ and concentration of octane is the highest with the value of $20.08 \mathrm{mg} / \mathrm{m} 3,60$ kinds of odour were discharged under $300^{\circ} \mathrm{C}$ and concentration of benzene is the highest with the value of $15.168 \mathrm{mg} / \mathrm{m} 3,48$ kinds of odour were discharged under $400^{\circ} \mathrm{C}$ and concentration of styrene is the highest with the value of $53.05 \mathrm{mg} / \mathrm{m} 3,58$ kinds of odour were discharged under $500^{\circ} \mathrm{C}$ and concentration of propylene is the highest with the value of 211.55 $\mathrm{mg} / \mathrm{m} 3,62$ kinds of odour were discharged under $600^{\circ} \mathrm{C}$ and concentration of pentane is the highest 
with the value of $2372.38 \mathrm{mg} / \mathrm{m} 3,61$ kinds of odour were discharged under $700^{\circ} \mathrm{C}$ and concentration of n-hexane is the highest with the value of $98.095 \mathrm{mg} / \mathrm{m} 3,48$ kinds of odour were discharged under $800^{\circ} \mathrm{C}$ and concentration of propylene is the highest with the value of $181.24 \mathrm{mg} / \mathrm{m} 3$, which can be seen from the figure 2 .

Besides, the total amounts of odour compositions under different thermal drying temperature were different too: the total amounts of odour compositions under $600^{\circ} \mathrm{C}$ were highest, associated with pyrolysis characteristics [15], followed by that under $600{ }^{\circ} \mathrm{C}$. The total amounts of odour compositions were less under $500^{\circ} \mathrm{C}$, therefore, in practical engineering, MSW thermal drying temperature should not be exceed than $400{ }^{\circ} \mathrm{C}$.

(3) Odor concentration under different thermal drying temperature

Odorous concentrations under different drying temperature were shown in figure 3.

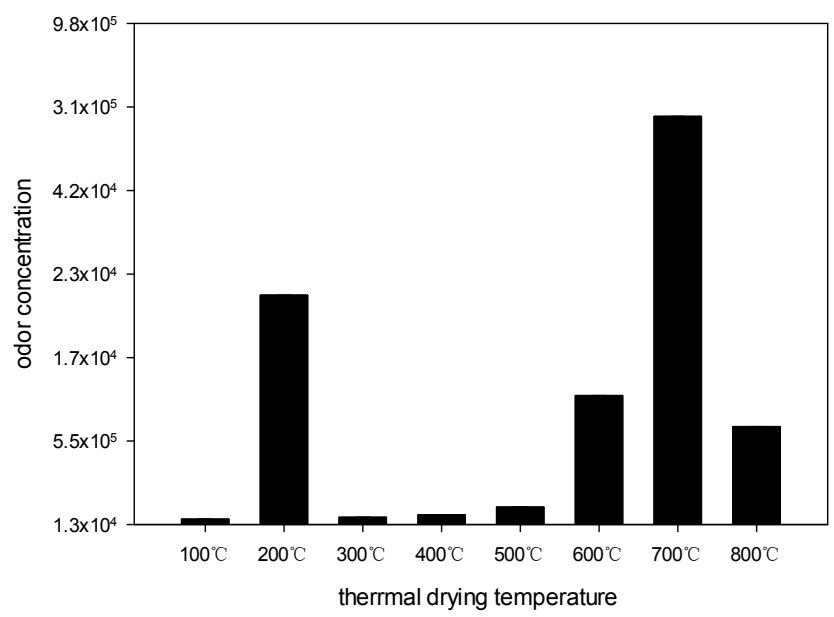

Fig. 3 odorous concentrations under different drying temperature

From figure 3 it can be known: the highest odour concentration were discharged under thermal drying temperature of $700^{\circ} \mathrm{C}$, followed by $200^{\circ} \mathrm{C}, 600^{\circ} \mathrm{C}$ and $800^{\circ} \mathrm{C}$. Odour concentration under $600^{\circ} \mathrm{C}$ was not the highest although the total amounts of odour compositions under $600^{\circ} \mathrm{C}$ were highest, it was because that odour concentration was related not only to the amount of compositions, but also to the olfactory threshold [16]. For the engineering application, comprehensive consideration of total amount of compositions and odour concentration, the advisable thermal drying temperature should be at $100^{\circ} \mathrm{C}, 300^{\circ} \mathrm{C}, 400^{\circ} \mathrm{C}$ and $500^{\circ} \mathrm{C}$.

\section{Conclusion}

Moisture content with manual flip mode dropped the lowest, so, rotary equipment will be preferred in the engineering of MSW thermal drying in order to quickly reduce the moisture content and improve the efficiency of the drying. The total amounts of odour compositions under $600^{\circ} \mathrm{C}$ were highest and were less under $500{ }^{\circ} \mathrm{C}$, therefore, in practical engineering, MSW thermal drying temperature should not be exceed than $400{ }^{\circ} \mathrm{C}$. The highest odour concentration were discharged under thermal drying temperature of $700{ }^{\circ} \mathrm{C}$, followed by $200{ }^{\circ} \mathrm{C}, 600{ }^{\circ} \mathrm{C}$ and $800{ }^{\circ} \mathrm{C}$. For the engineering application, comprehensive consideration of total amount of compositions and odour concentration, the advisable thermal drying temperature should be at $100^{\circ} \mathrm{C}, 300^{\circ} \mathrm{C}, 400^{\circ} \mathrm{C}$ and $500^{\circ} \mathrm{C}$.

\section{References}

[1] Diaz L F., Savage G M., Eggerth L L, Alternatives for the treatment and disposal of healthcare wastes in developing countries, Waste Management. 25(2005) 626-637. 
[2] Sun X J, Xu D m, L X et al, Analysis of Composition and Caloric Value of Municipal Solid Waste in Shanghai, JOU RNAL OF TONGJI U NIV ERSITY( NATURAL SCIENCE). 36(2008) 356-341.

[3] Li X D, Lu S Y, Xu X, Analysis on caloric value of Chinese cities municipal solid waste, China Environmental Science. 21(2001) 156-160.

[4] Ludvigsen, Anaerobic microbial redox processes in a landfill leachate contaminated aquifer,Journal of Contaminant Hydrology. 33(1998) 273-291.

[5] Min L., Jun X., Song H., et al, Characterization of solid residues from municipal solid waste incinerator, Fuel. 83(2004) 1397-1405.

[6] Kasahtra T, Hasatani M, Needs drying of sludge, Drying Technology. 14(1996) 1390-1392.

[7] Lahdeniemi A, Makela M, Dahl O, Drying /fractionation of deinking sludge with a high-velocity cyclone, Drying Technology. 31(2013) 378-384.

[8] Xiong Y G, Zhang K, Ding W J et al, The characteristics of odor and volatile organic compounds produced by the indirect drying of sludge, Environmental Chemistry. 33 (2014) 1046-1047.

[9] Deng M J, Chen W H, Luo H et al, Study on the characteristics of odor and volatile organic compounds produced by direct drying of sludge, Environmental science. 35(2014): 2897-2902.

[10] Eitzer B D, Emissions of volatile organic chemicals from municipal solid waste composting facilities, Environ Sci Technol. 29(1995) 896-902.

[11] Li C P, Fuzzy evaluation of optimum gasification temperature of sludge derived fuel, Advances in Environmental Technologies. (2013): 1239-1244.

[12] Caruth D, Klee A J, Analysis of Solid Waste Composition: Statistical Technique to Determine Sample Size. U. S. Department of Health: Education and Welfare, Public Health Service; 1969.

[13] Bindu N, Lohani S M Ko, Optimal sampling of domestic solid waste. Journal of Environment Engineering. 114(1998): 1479-1483.

[14] Gage J, Checklist for odor management at compost facilities, BioCycle. 44 (2003) 42-47.

[15] Arlabosse P, Chavez S, Prevot C, Drying of municipal sewage sludge: From a laboratory scale batch indirect dryer to the paddle dryer, Brazilian Journal of Chemical Engineering. 22(2005) 227-232.

[16] Zou KH, Pollution assessment technology and environmental standard, Beijing: Chemical Industry Press, 2013. 